\title{
EXTERNAL APPROPRIATION OF INNOVATIVE CAPABILITIES: THE PREFERENCE FOR STRATEGIC ALLIANCES OR M\&AS
}

\author{
JOHN HAGEDOORN and GEERT DUYSTERS
}

May 1999

We would like to thank participants at seminars at Maastricht University, Georgetown University School of Business, the Wharton School of the University of Pennsylvania, the Graduate School of Management, University of California at Irvine and Michael Hitt for their comments and suggestions on previous versions of the paper.

MERIT, Faculty of Economics and Business Administration, University of Maastricht, PO Box 616, 6200 MD Maastricht, The Netherlands - telephone (31)43-3883897- fax: (31)43-3216518 - email: j.hagedoorn@mw.unimaas.nl 


\section{EXTERNAL APPROPRIATION OF INNOVATIVE CAPABILITIES: THE PREFERENCE FOR STRATEGIC ALLIANCES OR M\&AS}

This paper explores the preferences that companies have as they use alternative external sources of innovative competences such as strategic technology alliances, mergers and acquisitions, or a mix of these. These alternatives are studied in the context of distinct industrial, technological and international settings. Different strategies followed by companies and the role played by routinized sets of preferences are also taken into consideration. The analysis demonstrates that these options are influenced by both different environmental conditions and firm specific circumstances, such as those related to protecting core businesses. 


\section{INTRODUCTION}

Strategic alliances and mergers and acquisitions (M\&As) have become well-known organizational instruments through which companies can increase their market power, enter into new markets or enhance their capabilities. The present contribution focusses on the basic research question: under which conditions do companies prefer strategic technology alliances, M\&As, or a combination of these, as alternative external sources of innovative capabilities? The relevance of our research for management studies is found in each of the major subjects mentioned in this basic research question. In recent years strategic alliances have grown in numbers, expressing the importance that this form of organization has for the strategies of many companies. M\&As have already been known to companies for a much longer period of time. As far as innovation is concerned, the effect of increased competition through new products and processes has been put on the agenda of both practitioners and academics.

Contributions that pay attention to the preferences of companies with regard to strategic alliances and M\&As usually analyse the conditions that affect the preference for either alliances (joint ventures in most contributions) or M\&As (Ingham and Thompson, 1994; Pisano, 1991). Our paper complements the current understanding in several ways. We examine strategic alliances that refer to a group of inter-firm modes of organization ranging from joint ventures to a variety of contractual agreements. In particular nonequity based alliances have become more important as it is estimated that in the late eighties and first half of the nineties nearly $80 \%$ of all strategic technology alliances are of a non-equity nature (Hagedoorn, 1996). Also, our analysis considers the preferences for alliances or M\&As for companies from different countries, whereas most studies concentrate on companies from one or two countries. Furthermore, our analysis focusses on 'technology' alliances which, according to the literature (Mowery, 1988; Mytelka, 1991), form an important class of alliances.

In the above we introduced concepts such as strategic technology alliances, M\&As and innovative 
capabilities for which it appears appropriate to give a short description. Strategic technology alliances are those modes of inter-firm cooperation for which a combined innovative activity or an exchange of technology is at least part of an agreement. Also, these alliances are expected to have an impact on the long-term product-market combinations of the companies involved. M\&As refer to cases of joint activities where two, once separate companies are combined into one company. This combination can refer to the merging of two more or less equal companies, as well as to acquisitions where one company obtains majority ownership over another company. Innovative capability concerns the specific expertise and competence related to the development and introduction of new processes and products.

\section{THEORY AND HYPOTHESES}

Contributions inspired by the resource-based theory of the firm (Wernerfelt, 1984; Rumelt, 1984) and the theory of dynamic firm capabilities (Nelson, 1991) stress the importance of unique, innovative company capabilities that create sustained performance differentials with other companies. Although we agree that these innovative capabilities are crucial to the company, we would like to add that the efficient use of external resources can also contribute to successful renewal within the company. Following Cohen and Levinthal (1989) we emphasize two important characteristics of the innovation process: one being the creation of new knowledge through endogenous R\&D efforts, the other being the ability to adopt existing technologies developed by others. At the intersection of endogenous and external technology development one finds strategic technology alliances where companies internalize knowledge and capabilities that are at least partially exogenous to them.

The attention for the role of strategic technology alliances as a mixture of both internal and external learning tools is found in a growing number of contributions (Gomes-Casseres, 1996; Hagedoorn, 1993; Mowery, 1988; Mytelka, 1991; Teece, 1992). Although differences do exist, all these contributions 
highlight the relationship between the increasing complexity of technological developments, that goes beyond the capabilities of most individual companies, and the use of external sources of technology through strategic technology alliances. In that context external resources for innovative renewal can complement endogenous capabilities and enable companies to cope with complex technologies through shared resources for increased learning capacity and improved innovative skills (Eisenhardt and Schoonhoven, 1996; Teece et al, 1997).

Apart from strategic technology alliances, full integration of innovative capabilities of other companies through M\&As remains another option. Recent contributions by Arora and Gambardella (1990), Haspeslagh and Jemison (1991) and Pisano (1991) point at the important role that M\&As can play when external sources of innovation have become relevant.

An understanding of the different options with regard to strategic technology alliances and M\&As can also be placed in the context of environmental influences shaping the behaviour of companies, as indicated by the structural contingency perspective (Donaldson, 1985; Lawrence and Lorsch, 1967) and the resource dependency view (Pfeffer and Salanzick, 1978). Then, environmental conditions are understood to limit the choices that companies have with regard to creating and shaping the organizational form that is needed. Not only does this suggest that organizations (including strategic technology alliances and M\&As) are embedded in their environment, it also suggests that companies have to take the effectiveness of different forms of organization into account.

We envision that an understanding of the effect of environmental conditions, inspired by a contingency perspective, and a perception of firm-specific conditions, motivated by the resource-based theory or the theory of dynamic firm capabilities, can aid in achieving a better understanding of preferences of companies. With different technological and industrial environments we expect a preference for strategic technology alliances and M\&As or a mix of these alternatives. However, the logic that we suggest also 
allows a substantial degree of discretion with companies to choose for strategic technology alliances or M\&As once they have been able to create safeguarded capabilities. The importance of understanding the environment of companies, their different strategies and capabilities, as well as the organizational choices they face, suggests the complexity that companies face in a world of technological, organizational and managerial change (Bettis and Hitt, 1995).

Further elaboration on these themes is necessary for a more detailed understanding of particular properties of the preference for strategic technology alliances and M\&As. These topics are discussed in more detail, referring to specific research questions, in the following sections.

\section{Sectoral differences in the preferences for M\&As and strategic technology alliances}

Recent contributions to the literature on different modes of organization suggest a sector-specific understanding of the association between, on the one hand, the level of technological change in sectors of industry, and, on the other hand, the form of economic organization, be it integration through M\&As or inter-firm linkages through strategic technology alliances. This implies that the effect of technological change in industries could have different implications in terms of the alternative modes of organization that companies choose if they intend to acquire external innovative capabilities.

Contributions by Eisenhardt and Schoonhoven (1996), Harrigan (1985), Link and Bauer (1991), Pisano (1991) and Teece (1992) demonstrate that the technological change that companies face is associated with a decreasing preference for integration and an increasing preference for flexible forms of organization such as alliances. Ciborra (1991) and Oster (1992) suggest that environments that induce or require a large degree of learning and flexibility, such as high-tech industries, will see a prevalence for alliances, whereas M\&As can be expected to be more popular in the low-tech sectors of industry, where learning and flexibility is less important than in high-tech industries.

Although these contributions differ with respect to the indicators used in the actual analysis, the 
general picture that emerges is one in which there is an association between the level of technological change in sectors of industry and the choice for particular modes of external appropriation of innovative competences. An explanation being offered is one in which under conditions of rapid technological change, as in the case of high-tech industries, learning, organizational change and quick strategic response ask for flexible forms of organization. These flexible forms of economic organization, such as strategic alliances, are appropriate because new knowledge expires quickly and timely learning from partners appears more appropriate than control through formal and hierarchical organization as such (Hagedoorn, 1993; Eisenhardt and Schoonhoven, 1996). However, under conditions of little technological change, as in socalled low-tech industries, companies demonstrate a preference for formal and well institutionalized modes of organization and control, such as M\&As, to be the most appropriate form of external appropriation of innovative capabilities. Under these latter conditions the external appropriation of innovative capabilities and the control over these new capabilities is well assured by means of integration through M\&As. This understanding of the effect of environmental conditions goes back to organization theory inspired by Lawrence and Lorsch (1967) and Pfeffer and Salancik (1978) which predicts that loose organizational structures, i.e. flexible organizations such as alliances, are more effective and better in adapting to changes under conditions of environmental uncertainty than integrated organizational structures such as M\&As.

Given the emphasis in this paper on technological change and company behaviour, the environmental conditions affecting the choice for M\&As or strategic technology alliances are expected to be found in different levels of technological sophistication and crucial differences in technological opportunities in industries. In the empirical literature (for instance, OECD 1992 and 1997) these different levels of technological sophistication and the differences in technological opportunities are identified for clusters of high-tech industries, medium-tech industries and low-tech industries. ${ }^{1}$ Following the logic for the association of the level of technological change in industries with the preference for particular modes 
of the appropriation as the main mechanism to transfer innovative capabilities, we expect a preference for strategic technology alliances in high-tech industries. We anticipate that in low-tech industries M\&As are the main form of inter-firm relationships. As medium-tech industries are by definition in between both other categories of industry sectors we expect that this position is reflected in a mix of strategic alliances and M\&As. Hence:

1a For companies operating in high-tech sectors, strategic technology alliances are preferred as a main mechanism for acquiring external innovative capabilities.

1b For companies operating in low-tech sectors, M\&As are preferred as a main mechanism for acquiring external innovative capabilities.

1c For companies operating in medium-tech sectors, the portfolio of external sources for acquiring innovative capabilities is of a mixed character of both strategic technology alliances and M\&As.

\section{Alternative strategies of companies regarding alliances and M\&As}

Apart from the effect of sectoral differences on the preferences of companies for strategic technology alliances or M\&As, there are also more firm specific and strategic conditions that influence the choices that companies make with regard to the external appropriation of innovative capabilities. These strategic considerations are particularly related to the question whether companies should be aware of the dangers of uncontrolled technology transfer to their partners in case of alliances in their core business, i.e. those activities that concern their major fields of industrial activity. If companies would need external sources of innovative capabilities that are related to their core business an M\&A might be the preferred option because this would, by definition, generate the necessary controls.

A number of contributions, from both a prescriptive and an analytical line of work, suggests different options for companies (Chi, 1994, Ingham and Thompson, 1994, Roberts and Berry, 1985 and Teece, 1986 and 1987). First of all, it is crucial for a company, that considers a strategic technology 
alliance or an M\&A, to know whether this refers to a core business activity or not. If the innovative capabilities of the other party involved and the joint effort itself are not critical to a company because they do not affect a core business, an alliance is the preferred option. M\&As are suggested in case the activities of (potential) partners are more important to the core business of the company and when increasing contracting costs and risks are involved. Then, the need for control over innovative capabilities related to core businesses suggests a formal mode of economic organization such as an M\&A as the most appropriate form for getting access to external sources of innovation. Hence:

2 External sources of innovative capabilities of companies related to core businesses will take the form of M\&As; for non-core businesses they will take the form of strategic alliances.

Another important factor that should be considered is the degree to which companies are able to protect their own innovative capabilities. If a company would engage in strategic technology alliances without having some protection over its own innovative capabilities, it could run the risk of uncontrolled transfer of knowledge and capabilities to its partner. It is in particular this risk of the unintended transfer of knowledge, that goes beyond the formally agreed transfer in an alliance, that has made some observers (Hamel, 1991; Reich and Mankin,1984) suspicious about the mutual benefits of strategic technology alliances. The ability of a firm to protect its innovative capabilities could be an important factor in understanding the organizational choices that companies should make in order to avoid the risk of unintended technology transfer.

If we understand a companies' core business as its major field of interest, we can follow Teece (1986 and 1987) where the regime of appropriability or the degree to which companies can protect their innovative capabilities, for instance through patents or trade secrets, is seen as a crucial factor in understanding the choice that companies make with regard to strategic technology alliances, M\&As, or mixed strategies. $^{2}$ A strong regime of appropriablity, that protects companies from quick imitation, leads 
to a preference for strategic alliances because companies are safeguarded against opportunistic behaviour of partners. Little or no protection through a weak regime of appropriability suggests that M\&As are a better mechanism for appropriating sources of innovation because partners can be controlled through ownership. Intermediate levels of protection will be related to mixed strategies with both strategic technology alliances and M\&As. The strength or weakness of a regime of appropriability for an individual company is then dependent on the degree to which a company can protect its innovative capabilities from its competitors (Lee et al, 1995). The logic behind the strategic use of different forms of economic organization implies that, controlling for sectoral differences, companies that have higher levels of protection than other companies can form alliances with less risk than those companies that find little protection for their innovative capabilities. Hence:

$3 a$ External sources of innovative capability appropriation of companies related to their core businesses will take the form of strategic technology alliances if their particular regime of appropriability in these core activities is above industry average

$3 b \quad$ External sources of innovative capability appropriation of companies related to their core businesses will take the form of M\&As if their particular regime of appropriability in these core activities is below the industry average.

3c External sources of innovative capability appropriation of companies related to their core businesses will take the form of a mix of alliances and M\&As if their particular regime of appropriability in these core activities is at the industry average.

\section{Routines of strategic technology alliance and M\&A strategies}

Another aspect of company specific characteristics in the preference for alliances, M\&As or a mix refers to the routines that companies develop during a number of years. In analogy to technological path dependencies (Arthur, 1989) we can understand organizational strategies in terms of idiosyncratic 
behaviour and organizational path dependencies where companies reinforce their existing innovative capabilities by concentrating on strategic technology alliances, M\&As or a combination of both as they are locked into a particular set of preferences. Osborn and Hagedoorn (1997) state that from the perspective of institutionalization theory it can be expected that companies search for 'rules of conduct' with regard to different forms of organization that are not only embedded in particular industrial settings but that are also copied over time as they become institutionalized within companies.

Research by Harrigan and Newman (1990) indicates that the propensity of firms to seek alliances is an important characteristic of differences with respect to the behaviour of firms in this context. Following Powell et al (1996) we expect experience with strategic alliances to have a positive effect on the choice for alliances as a mechanism for the external appropriation of innovative capabilities. The same can be expected for the history that firms have with regard to M\&As. Trautwein (1990) found that a developed set of organizational routines with a preference for M\&As will make firms, that have established these routines, to increasingly engage in M\&A formation. In other words, routines of alliance or M\&A activities in the past affect the degree to which firms are momentarily active in forming strategic technology alliances and/or M\&As. Hence:

4 The history of companies, in terms of routines with a preference for $M \& A s$, strategic technology alliances, or a mix, determines their current preference for each of these modes or a combination of them, as a main strategic mechanism for acquiring additional capabilities.

\section{RESEARCH METHODS}

\section{Sample}

The population of companies that we analyse consists of a group of 135 large US, Canadian and European companies. We did not include Japanese and Korean companies in this study because most of these 
companies are of a very widely diversified nature, ranging from raw materials to consumer products and financial and other services, which makes it impossible to denote their core business or relate them to any sort of industry classification. An initial screening of US, Canadian and European companies from the Business Week and Fortune 500 lists of international companies was set up to find those companies that had formed a minimum of five strategic technology alliances and/or M\&As during the period 1993-1994. For obvious reasons companies with neither strategic technology alliances or M\&As were not relevant for this particular line of research. For companies with less than five alliances and/or M\&As we found it too precarious to discern whether they followed a strategy that could be characterized as mainly oriented towards strategic technology alliances, M\&A, or a mixed strategy. ${ }^{3}$ Under these restrictions a sample of 153 companies remained as the population to be studied, 18 companies from this sample were excluded from the statistical analysis due to missing values.

As mentioned above the sample consists of large firms that have established strategic technology alliances, M\&As or both. There is a well-established body of literature on the prominent role that, in particular, large firms play in forming strategic alliances, see Berg et al (1982), Duysters and Hagedoorn (1995), Ghemawat, Porter and Rawlinson (1986), Hagedoorn (1995), Mowery (1988) and Mytelka (1991). Research by Haspeslagh and Jemison (1991), Hoskisson and Hitt (1994), Ingham and Thompson (1994), Mueller (1986) and Salter and Weinhold (1979) indicates that in general the same holds for M\&As where large firms are the acquirers and small firms are acquired. ${ }^{4}$

\section{Data sources}

The data on strategic technology alliances and characteristics of companies involved in these alliances is derived from the MERIT-CATI data bank on strategic technology alliances. The database currently covers the period between 1970 and 1994 and contains information on nearly 13000 strategic technology alliances. The most important data sources are international and specialized trade and 
technology journals for each sector of industry and many fields of technology. Strategic technology alliances are defined as the establishment of common interests between independent (industrial) partners which are not connected through (majority) ownership. Although an alliance can cover a number of activities, the transfer of technology or the undertaking of joint research has to be part of the arrangement. Mere production or marketing alliances are excluded. Examples of strategic alliances are joint research pacts, joint development agreements, R\&D contracts, (mutual) second sourcing agreements and joint ventures with technology sharing or an R\&D program. The differentiation between strategic alliances and other forms of cooperation in this data bank is described extensively in Hagedoorn (1993). As the share of joint ventures in the total number of strategic technology alliances has dropped to about $20 \%$ in the nineties (Hagedoorn, 1996), the data for joint ventures had to be combined with the contractual alliances to avoid statistical problems related to small numbers.

Key-characteristics of companies, such as size and core business, were imported from Securities Data files (see next paragraph). Within the CATI data base there are 65 classifications with respect to sub-sectors and sub-fields of technology that can also be identified in terms of SIC codes and patent classifications, see Appendix A. For the purpose of the present analysis information was used regarding the industrial sectors in which companies operate, their core business, the year of establishment of the strategic technology alliance and the industry affiliation of the alliance.

The second data bank provides information on M\&As. This data bank is property of Securities Data and can be used via on-line access. It contains information on about 125.000 worldwide M\&As for the period 1980-1994. This information is arranged in several data files. The relational form of the data base facilitates the linking of these data files to each other and also to files in other data banks. Within the M\&As data base there is information on the year the M\&A was established and on the acquirer, the target, the parent acquirer and the parent target firm. The industry information is provided 
in SIC codes of the aquiree and acquirer.

As we analyse the preference for strategic technology alliances, M\&As, or a mix, we had to select a population of M\&As that can be expected to have a similar strategic and technological focus as strategic technology alliances. Chatterjee (1986) established that completely unrelated and conglomerate M\&As are created because of financial synergies from a perspective of portfolio management for which strategic, operational and technological synergies are implausible. For related horizontal and vertical M\&As these strategic, operational and technological synergies, based on economies of scale and scope, were found to be most relevant. Following this line of research, a selection of M\&As from the Securities Data data bank was made to denote vertically and horizontally related M\&As of the companies in the sample. M\&As with companies from service industries, where diffusion of innovations might be relevant but where technical innovation itself is of limited relevance, were excluded. An exception was made for M\&As with companies from service industries that do have a profile of endogenous innovative capabilities, such as software and engineering services and R\&D services, which were included, see Appendix B. For instance, we combined M\&As in computer related services and $R \& D$ and testing services with $M \& A s$ in the appropriate high-tech sectors. M\&As in engineering services were joined with M\&As in other medium-tech industries. Furthermore, using the brief description of the objectives of the M\&As in the Securities Data data bank, we selected those M\&As for which innovation, R\&D or technology were mentioned in the description of the individual M\&A. Following the above we developed a group of M\&As that are comparable in scope to the group of strategic technology alliances. The relevant sectors, however, represent not only high-tech sectors but also medium-tech and low-tech sectors, see Appendix A.

Finally, the patent data refers to US patent data obtained from the US Department of Commerce, which covers the period 1992-1993. Although this US data could imply a bias in favour 
of US companies and against non-US firms, the group of non-US companies in this study represents a group of very large, international firms which are known to patent world wide. Furthermore, the innovation literature ( for instance, Patel and Pavitt, 1991) suggests several other reasons to take US patents as an indicator. Frequently mentioned are the importance of the US market, the 'real' patent protection offered by US authorities, and the level of technological sophistication of the US market which makes it almost compulsory for non-US companies to file patents in the USA.

\section{Variables and measures}

Sectors of industry. We defined sectors as high-tech, medium-tech, or low-tech following the standard OECD sector-classification (OECD, 1997) and similar classifications that feature in many innovation studies (Hagedoorn, 1993; OECD, 1992; Osborn and Baughn, 1990; Verspagen, 1995) which group sectors as to their level of technological sophistication in terms of R\&D intensity. Following this classification, companies in our analysis that are in pharmaceuticals (with an R\&D intensity of 10.5\%), information technology (11.5\%), aerospace/defense (15.0\%) are in high-tech industries; instrumentation (5.1\%), chemicals/plastics $(3.4 \%)$ and automotive (3.4\%) are taken as medium-tech industries; food and beverages $(0.3 \%)$, metals $(0.6 \%)$, oil and gas $(0.9 \%)$ are low-tech industries. The figures in between brackets are $R \& D$ intensity indicators, $R \& D$ expenditures as \% of value of production, for 1990 as found in OECD (1997). As shown by these R\&D intensity indicators this selection procedure leads to three clearly different groups of sectors for companies in the analysis

Regime of appropriability or patent intensity of core businesses. The regime of appropriablity is measured through the patent intensity of companies. We are aware that patents are not the only means of protection against opportunistic behaviour and that the relevance of patenting differs with regard to sectors (Teece, 1987; Winter, 1987; Bettis and Hitt, 1995). Winter (1987) presents a quantitative analysis of different levels of patent protection for a large number of industries. However, this overview 
of the effectiveness ratings for patent protection also indicates that for most industries that we analyze patents are still found to be effective or moderately effective. Other contributions to the literature do support the notion of patenting as still one of the most effective means of protecting a firm's innovative capabilities, which also indicates the ability of companies to introduce new products and processes (Napolitano and Sirilli, 1990, Patel and Pavitt, 1995). Also, the patent indicator is the only measure that enables researchers to make a general comparison, contrary to indicators such as trade secrets which remain rather vague or copyrights that are only relevant in a limited number of sectors. Moreover, given similarities of patent protection within industries and in one leading nation (the USA), the role of patent protection for companies in similar industries does suggest that patent intensity indicates the degree to which particular companies can protect their innovative capabilities, demonstrating their relative position with regard to regimes of appropriability, see also endnote 2 . The use of patent intensity as an indicator of strength in product development also allows us to control for different innovative capabilities.

The patent intensity of companies during the period 1992-1993 is calculated as the patent intensity of a firm in its core business (number of patents divided by a firm's turnover in its core business) adjusted for the average patent intensity of firms in our sample that operate in the same sector, to take sectoral differences with respect to patenting behaviour into account. This patent intensity ratio of companies is divided by the sectoral standard deviation. ${ }^{5}$ This generates a normalized range with an average of 0 and a standard deviation of 1 . Firms with a score of less than -0.5 have a low patent protection, those with a score higher than 0.5 are patent intensive firms, those with a score between -0.5 and 0.5 take an intermediate position. In order to determine the core business of the companies we used the information of the SIC codes of their main business, usually at a combined SIC 3-digit level, as registered in the Securities Data data set, see Appendix A. 
Strategic technology alliances and M\&As in core businesses. For each company we calculated the share of its strategic technology alliances that are undertaken in its core business and the share of its M\&As that take place in its core business during the years 1992 and 1993. Core businesses were determined in a similar way as with the previously discussed measure, using the information of the SIC codes of their main business, usually at a combined SIC 3-digit level, as registered in the Securities Data data set, see Appendix A.

Routines of strategic technology alliances and $M \& A$ strategies. The history of companies, in terms of routines with a preference for M\&As, strategic technology alliances, or a mix was calculated by applying the following set of rules to denote the preference for the individual years 1985-1992. The strategic technology alliances of a firm are set against its combined number of strategic technology alliances and M\&As in each year. This percentage is set against the average for its sector to account for sectoral differences in the propensity to engage in external relationships. Next, this ratio is divided by the sectoral standard deviation. This generates a normalized range with an average of 0 and a standard deviation of 1 . Firms with a score of less than -0.5 have a preference for M\&As, those with a score between -0.5 and 0.5 have a mixed strategy, and those with a score higher than 0.5 concentrate on alliances, in a specific year. After we determined the preferred strategy for every single year, we calculated how many times companies used a particular strategy. The overall distribution of these different strategies for each individual company determines the value of the variables for strategic technology alliance routines, M\&A routines and mixed routines.

International differences. We controlled for differences between US and non-US companies using a dummy variable to indicate whether companies are registered as US companies or not (USA dummy). Hagedoorn and Schakenraad (1994) found that European and US firms are not different with regard to the degree to which they engage in strategic technology alliances if one controls for size of 
companies. However, the literature (e.g. Odagiri and Hase, 1989; Milgrom and Roberts, 1992) does suggest differences with respect to the (history of) M\&A behaviour of European and US companies as the latter are known to be more engaged in M\&As than their international competitors.

Size of companies. We also controlled for size differences in the sample of companies because, as explained above, previous research indicates that size does play a role in this context as the intensity of both partnering and M\&As appears to increase with size of companies. However, there is little to be said about what effect size will have on the choice for each of the alternative strategies. The average size of companies during the years 1992 and 1993 is measured by means of the $\log _{\mathrm{n}}$ of world wide sales. Logarithms are taken to correct for a small number of very large companies in our sample.

The preference for strategic technology alliances, $M \& A s$ or a mix. The dependent variable in our analysis refers to the preference of companies for strategic technology alliances, M\&As or a mix of both. The set of rules applied to measure the routines of strategic technology alliances, M\&As or mixed strategies, discussed above, is also used to determine the preference for strategic technology alliances, M\&As or a mix. This dependent variable covers the years 1993 and 1994.

Finally, it is important to note that conditions of uncertainty do not only relate to technological development but also to the degree of internationalization that might affect the preference for certain modes of organization. Controlling for different levels of technological change in sectors, domestic external relationships could be expected to be dominated by strategic technology alliances. M\&As could be expected to be applied the more a company engages in the internationally distant external appropriation of innovative capabilities (Dunning, 1993). However, we expect that the population of companies under study is already that internationalized that, within the context of the present study, we can assume that their level of international activities would not discriminate in terms of a preference for particular modes of organization. ${ }^{6}$ 


\section{Analysis}

As most of our research questions imply that we have a dependent variable with three categories, we apply multinomial logit analysis (Limdep 7.0). ${ }^{7}$ As mentioned above, the period that we analyse refers to the period 1992 and 1993 for the independent variables with the exception of the routines of firms with respect to alliances and M\&As for which the period 1985-1992 was chosen. The short period of two years for all but one variable was taken because with longer periods the choice companies made with respect to M\&As could affect the measurement of independent variables such as those related to innovative capabilities and core businesses because these very companies would change due to their M\&As. For the dependent variable, the preference for strategic technology alliances, M\&As or a mix, we took the period 1993-1994 to allow for a short time-lag with the independent variables.

Hypothesis 2 will be tested separately with a t-test for paired samples to compare differences between two groups. This separate test is necessary because hypothesis 2 refers to the preference for either strategic technology alliances or M\&As. This paired t-test allows us to test the hypothesis that the average number of M\&As (as a percentage of the total number of M\&As) that is found in the core business of companies is significantly higher than the average number of strategic technology alliances (as a percentage of the total number of alliances) in the core business of companies. The period 19921993 is identical to the period for most of the independent variables in the other test.

\section{RESULTS}

We will first, briefly, present some descriptive data on the population. As mentioned above, there are 135 companies in the final analysis. $31 \%$ of these are non-US companies, the others are US firms. 55\% of the companies have their core business in high-tech sectors, $31 \%$ are mainly active in medium-tech sectors and $14 \%$ are categorized by their core business as low tech companies. $37 \%$ of the companies 
in this population follow an alliance strategy, 37\% concentrate their external activities on M\&As and about $26 \%$ follow a mixed strategy.

A multinomial logit model is used to analyse which factors determine the probability that firms prefer one of the three strategies. The estimation results are presented in tables 1 and 2 . The first two columns show the estimated coefficients and z-scores for the probability that a firm takes on a M\&A or mixed strategy, respectively, with the alliance strategy as reference state. The third column shows the estimation coefficients and z-scores for the probability that a firm takes on a mixed strategy, with the M\&A strategy as the reference state (it contains the differences between the coefficients for M\&A and mixed strategies and corresponding z-scores). This column shows the effects of variables on the probability that a firm takes on a mixed strategy and not a M\&A strategy.

Our initial analysis detected strong multicollinearity of the variables for routines with the other variables. Therefore, the effect of routines (hypothesis 4) is tested separately. The results of this second analysis is shown in table 2 . Table 1 shows the effects of the other variables. Some additional information is presented in table 3 where the actual group means are given.

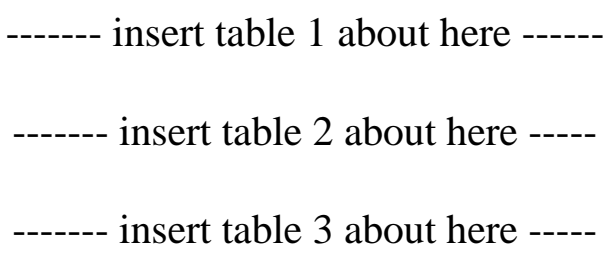

The results of the multinomial logit analysis indicate some significant differences with regard to the differentiation of low-tech, medium-tech and high-tech sectors and the preference for strategic technology alliances, M\&As or a mixed option. Companies that prefer strategic technology alliances over M\&As are primarily active in high-tech sectors, companies that favour M\&As over alliances are mostly found in the low-tech sectors (see tables 1 and 3). Companies that have a mixed strategy preference over M\&As are primarily active in medium-tech sectors; companies that have a mixed 
strategy preference over alliances, however, cannot be assigned to medium-tech sectors. These results confirm hypotheses $1 \mathrm{a}$ and $\mathrm{b}$ and generate partial support for hypotheses $1 \mathrm{c}$.

The variables indicating different degrees of patent intensity in core activities, however, all generate clearly insignificant results, see table 1 . The expected effects of regimes of appropriability on preferences with respect to strategic technology partnerships, M\&As or mixed portfolios (hypotheses 3a-c) could not be detected.

As far as country differences are concerned, our analysis does not generate significant differences between US and European companies (see USA dummy) with respect to their propensity to choose primarily strategic alliances or M\&As. However, the other control variable, size, does show a significant effect as the preference for M\&As decreases with the size of companies

There are highly significant differences with respect to the history of companies in terms of strategic technology alliances, a mix of strategic technology alliances and M\&As, or a long-term propensity to engage primarily in M\&As indicating a particular preference for a long-term strategy based on strategic technology alliances, M\&As or a mix (see table 2). This indicates that hypothesis 4 is confirmed by our analysis.

The results of the t-test for paired samples, see table 4, indicate significant differences between the average scores on core business-related strategic technology alliances and the average score on core business M\&As, which confirms hypothesis 3.

insert table 4 about here

\section{DISCUSSION}


A summary of the support for the hypotheses tested in this paper is given in table 5 . insert table 5 about here

This study demonstrates that the industrial and technological environment in which companies operate plays a role in explaining why companies have a preference for more flexible forms of organization such as strategic technology alliances, a mix of these alliances and integration, or straightforward integration by means of M\&As. The more companies have their core businesses in high-tech sectors, such as pharmaceuticals, information technology and aerospace/defense, the more they are inclined to engage in strategic technology alliances. With low levels of the technology-intensity of sectors, such as in food and beverages, metals and oil and gas, integration of external sources of innovation by means of M\&As becomes more important. For medium-tech industries, such as the automotive, instruments and chemical industries, mixed strategies are preferred over strongly M\&A oriented strategies.

Against this background we can also consider the question whether companies prefer the option of integration through M\&As, if external sources of innovative capabilities affect their core businesses, or whether they choose for strategic technology alliances with respect to these core activities. The literature, both from an analytical and a prescriptive perspective, seems to suggest that companies should play it safe and use M\&As for core businesses in order to avoid uncontrolled technology transfer. Strategic technology alliances should be applied for other activities, that can, of course, eventually become core businesses. Our analysis suggests that most companies operate rather rational, that is conform to what theory would expect. They prefer M\&As as external sources of innovation for their core businesses and they demonstrate a higher preference for strategic technology alliances in their other businesses. 
The issue of the relationship between the degree to which companies are able to protect their internal innovative capabilities through a particular regime of appropriability, on the one hand, and their preference for each of the three options with regard to the use of external sources of innovative capabilities, on the other hand, is more problematic. As far as our analysis is concerned there seems to be no relationship between the degree to which companies are able to protect their innovations and their preferences for strategic technology alliances, M\&As or a mix. We still think that the regime of appropriability is an important strategic factor that will enter into the equation if companies decide what precise form of external relationships they prefer. However, it seems that a somewhat aggregated level of analysis, as in this study, using only patenting is probably less appropriate for an analysis that includes the regime of appropriability. In depth studies of particular cases with different case-specific indicators, as found in Teece (1987), are in all likelihood more adequate to illustrate the strategic importance of the regime of appropriability in the context of attempts to augment a firm's innovative capabilities through different external sources.

However, the importance of firm specific capabilities, but now in terms of routinized behaviour that has become institutionalized within the firm, is found to have a very significant effect with regard to organizational preferences of companies. Our analysis indicates that, as with so many other aspects of their behaviour, companies seem to stay with certain routines. Companies that have a relatively long history of systematic preference for one of the options for the external appropriation of innovative capabilities seem to stick to their preference. We think this indicates that companies are quite satisfied with their past preferences and that these preferences for particular modes of external appropriation of innovative capabilities fit quite well with their overall innovation strategy. It seems unlikely that companies simply maintain their routines without considering alternatives. Particularly this group of 
large companies can be expected to be aware of the alternative options.

\section{CONCLUSIONS}

As far as questions about the industry (environment) versus company (strategy) effects are concerned, our study supports those approaches that stress the relevance of both company-specific and environmental factors (Eisenhardt and Schoonhoven, 1996). It suggests a moderate resource-based theory of the firm in its understanding of organizational properties where, as also suggested by the classical resource dependency approach, alternatives in organizational forms have to be evaluated against the background of environmental conditions. Our findings also support contributions from a variety of theoretical approaches, such as those that combine elements of evolutionary economic theory with an understanding of the effects of strategic behaviour, theories developed from an organizational learning and technology perspective, and work done in the context of institutional organization theory that pays attention to the impact of environmental conditions on alternative forms of organization.

What we witness in the present analysis is, on the one hand, environmental conditions that influence the general preferences of companies, and, on the other hand, firm specific conditions that lead to a particular group of relationships. Although firms could use a 'random' portfolio of options, in terms of any mix of strategic technology alliances and M\&As, there is a clear pattern for the group of large companies that we investigated. There are distinct environmental contingencies in terms of the level of technology intensity of sectors in which companies operate. With increasing technology intensity of sectors of industry, the flexibility found in alliances, with the opportunity this provides to learn through loosely structured agreements, appears more important than formal control through full ownership. This formal control appears more appropriate in low-tech sectors. However, these routinized 
preferences are influenced by the degree to which strategic technology alliances and M\&As are related to the core businesses of companies. If the external sourcing of innovative capabilities comes closer to the core business of companies, the role of integration becomes more important because in that case M\&As provide greater control than strategic technology alliances. This does not imply that companies completely reverse the distribution of alliances and M\&As. However, increased control through a greater input from integrative modes appears still useful if companies want to protect their interests in external relationships affecting their core business that will constitute their competitive strength for some time to come.

The above also clarifies how one can, for instance, explain the examples of well-known hightech companies that are engaged in a relatively large number of M\&As. Our analysis demonstrates that in general companies in high-tech industries have a preference for strategic alliances. This does not imply that they are not engaged in M\&A activities, however, their alliances outnumber the number of their M\&As. Moreover, our analysis indicates that also high-tech industries companies prefer M\&As if the external appropriation of innovative capabilities is related to their core business.

It is obvious that all of this has to be seen in the light of certain limitations of this study. A brief discussion of these limitations enables us to introduce some interesting topics for further study. First of all, subsequent work could study the role of M\&As and strategic alliances in a larger model than the one applied in this study, where the interacting effects of both internal and external innovation and governance mechanisms on company performance are examined. Recent contributions such as Hitt et al (1996) seem an interesting starting point for such a broader setting. Second, more in-depth analysis of different forms of M\&As and alliances in terms of their relatedness to different businesses at a disaggregated level within the company could provide more in-depth understanding of the effect of M\&As 
and alliances on innovation and company performance. Such detailed studies would probably require survey research of companies to replace or complement database research such as undertaken in the current study. However, the results of our research present the broader picture regarding alternative organizational strategies and different industrial settings against which this subsequent research can be placed. 


\section{REFERENCES}

Arora, A. and A. Gambardella, 1990, Complementary and external linkages: the strategies of large firms in biotechnology, Journal of Industrial Economics, 38, pp. 361-379.

Arthur, B., 1989, Competing technologies, increasing returns, and lock-in by historical events, The Economic Journal, 99, pp. 116-131.

Berg, S.V., J. Duncan and P. Friedman, 1982, Joint venture strategies and corporate innovation, Cambridge, Oelgeschlager, Gunn \& Hain.

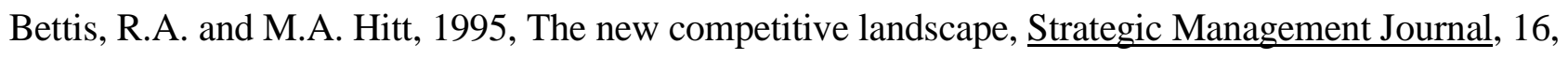
pp. 7-19.

Chatterjee, J.S., 1986, Types of synergy and economic value: the impact of acquisitions on merging and rival firms, Strategic Management Journal, 7, pp. 119-139.

Chi, T., 1994, Trading in strategic resources: necessary conditions, transaction cost problems, and choice of exchange structure, Strategic Management Journal, 15, pp. 271-290.

Ciborra, C., 1991, Alliances as learning experiments: cooperation, competition and change in high-tech industries, in L.K. Mytelka (ed.), Strategic partnerships and the world economy, London, Pinter, pp. 51-77.

Cohen, W. and D. Levinthal, 1989, Innovation and learning: the two faces of R\&D, The Economic Journal, 99, pp. 569-596.

Donaldson, L., 1985, In defense of organisational theory, Cambridge, Cambridge University Press.

Dunning, J., 1993, Multinational enterprises and the global economy, Wokingham, Addison Wesley. Duysters, G. and J. Hagedoorn, 1995, Strategic groups and inter-firm networks in international hightech industries, Journal of Management Studies, 32, pp .361-381.

Eisenhardt, K.M. and C. B. Schoonhoven, Resource-based view of strategic alliance formation: strategic and social effects in entrepreneurial firms, Organization Science, 7, pp. 136-150.

Ghemawat, P., M.E. Porter, and R.A. Rawlinson, 1986, Patterns of international coalition activity, in M.E. Porter (ed.), Competition in global industries, Boston (MA), Harvard Business School Press, pp. 345-365.

Gomes-Casseres, B., 1996, The alliance revolution: the new shape of business rivalry, Cambridge (MA), Harvard University Press.

Hagedoorn, J., 1993, Understanding the rationale of strategic technology partnering: inter- 
organizational modes of cooperation and sectoral differences, Strategic Management Journal, 14, pp. 371-385.

Hagedoorn, J., 1995, A note on international market leaders and networks of strategic technology partnering, Strategic Management Journal, 16, pp. 241-250.

Hagedoorn, J., 1996, Trends and patterns in strategic technology partnering since the early seventies, Review of Industrial Organization, 11, pp. 601-616.

Hagedoorn, J. and J. Schakenraad, 1994, The effect of strategic technology alliances on company performance, Strategic Management Journal, 15, pp.291-311.

Hamel, G., 1991, Competition for competence and inter-partner learning within international strategic alliances, Strategic Management Journal, 12, pp. 83-103.

Harrigan, K.R., 1985, Strategies for joint ventures, Lexington, Lexington Books.

Harrigan, K.R. and W.H. Newman, 1990, Bases of interorganization co-operation: propensity, power, persistence, Journal of Management Studies, 27, pp. 417-434.

Haspeslagh, P. and D. Jemison. 1991, Managing acquisitions: creating value through corporate renewal, New York, Free Press.

Hitt, M.A., R.E. Hoskisson, R.A. Johnson and D.D. Moesel, 1996, The market for corporate controland firm innovbation, Academy of Management Journal, 39, pp. 1084-119.

Hoskisson, R. and M.A. Hitt, 1994, Downscoping - how to tame the diversified firm, Oxford, Oxford University Press.

Ingham, H. and S. Thompson, 1994, Wholly-owned vs collaborative ventures for diversifying financial services, Strategic Management Journal, 15, pp. 325-334.

Lawrence, P.R. and J.W. Lorsch, 1967, Organization and environment, Cambridge (Ma), Harvard University Press.

Lee, J-R, D.E. O’Neal, M.W.Pruett, H. Thomas, 1995, Planning for dominance: a strategic perspective

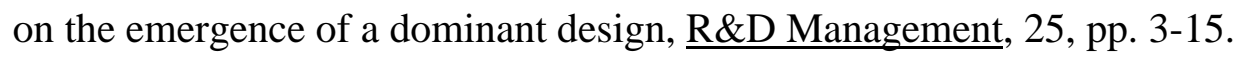

Link, A. N. and L. L. Bauer. 1989. Cooperative research in U.S. manufacturing: assessing policy initiatives and corporate strategies. Lexington, Lexington Books.

Milgrom, P. and J. Roberts, 1992, Economics, organization and management, Englewood Cliffs (NJ), Prentice-Hall.

Mowery, D.C. (ed.), 1988, International collaborative ventures in U.S. manufacturing, Cambridge, 
Ballinger.

Mueller, D.C., 1986, The modern corporation - profits, power, growth and performance, Brighton, Wheatsheaf Books.

Mytelka, L.K. (ed.), 1991, Strategic partnerships and the world economy, London, Pinter.

Napolitano, G. and G. Sirilli, 1990, The patent system and the exploitation of inventions: results of a statistical survey conducted in Italy, Technovation, 10, pp. 5-16.

Nelson, R., 1991, Why do firms differ, and how does it matter?, Strategic Management Journal,12, pp. $61-74$.

Odagiri, H. and T. Hase, 1989, Are mergers and acquisitions going to be popular in Japan? An empirical study, International Journal of Industrial Organization, 7, pp. 49-73.

OECD. 1992. Technology and the economy. Paris, OECD.

OECD, 1997, Revision of the high technology sector and product classification, Paris, OECD.

Osborn , R. N. and C. Baughn, 1990, Forms of inter-organizational govenance for multinational alliances, Academy of Management Journal, 33, pp. 503-519.

Osborn, R.N. and J.Hagedoorn, 1997, The institutionalization and evolutionary dynamics of interorganizational alliances and networks, Academy of Management Journal, 40, pp. 261-278.

Oster, S.M., 1992,Modern competitive analysis, New York, Oxford University Press.

Patel, P. and K. Pavitt, 1991, Large firms in the production of the world's technology: An important case of 'non-globalization, Journal of International Business Studies, 22, pp. 1-21.

Patel, P. and K. Pavitt, 1995, Divergence in technological development among countries and firms, in J. Hagedoorn, Technical change and the world economy, Aldershot, Edward Elgar, pp. 147-181. Pfeffer, J. and Salancik, 1978, The external control of organizations, New York, Harper and Row. Pisano, G.P., 1991, The governance of innovation: vertical integration and collaborative arrangements in the biotechnology industry, Research Policy, 20, pp. 237-249.

Powell, W.W., K.W. Koput and L. Smith-Doerr, 1996, Interorganizational collaboration and the locus of innovation: networks of learning in biotechnology, Administrative Science Quarterly, 41, pp. 116145.

Reich, R. B. and E.D. Mankin, 1984, Joint ventures with Japan give away our future, $\underline{\text { Harvard Business }}$ Review, March- April, pp. 78- 86.

Roberts, E.R. and C.A. Berry, 1985, Entering new businesses: selecting strategies for success, $\underline{\text { Sloan }}$ 
Management Review, 26, pp. 3-17.

Rumelt, R.P., 1984, Toward a strategic theory of the firm, in R. Lamb (ed.), Competitive strategic management, Englewood Cliffs(NJ), Prentice Hall, pp. 556-570.

Salter, M.S. and W.A. Weinhold, 1979, Diversification through acquisition - strategies for creating economic value, New York, Free Press.

Teece, D., 1986, Profiting from technological innovation, Research Policy, 15, pp. 286-305.

Teece, D.J., 1987, Profiting from technological innovation: implications for integration, collaboration, and public policy, in D.J. Teece (ed.), The competitive challenge, Cambridge (Ma.), Ballinger.

Teece, D.J., 1992, Competition, cooperation, and innovation, Journal of Economic Behavior and Organization, 18, pp. 1-25.

Teece, D.J., G. Pisano and A. Shan, 1997, Dynamic capabilities and strategic management, Strategic Management Journal, 18, 509-533.

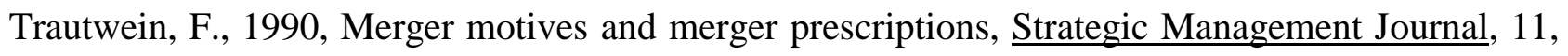
pp.283-295.

Verspagen, B., 1995, R\&D productivity: a broad cross-section, cross-country outlook, Journal of Productivity Analysis, 6, pp. 117-135.

Wernerfelt, B., 1984, A resource based view of the firm, Strategic Management Journal, 5, p.171-180. Winter, S.G., 1987, Knowledge and competence as strategic assets, in D.J. Teece (ed.), The competitive challenge, Cambridge (Ma.), Ballinger, pp. 159-184. 
APPENDIX A

Table of concordance between sectors in CATI, Securities Data M\&As, and US Patent data

\begin{tabular}{|c|c|}
\hline Industries & Patent classifications \\
\hline \multicolumn{2}{|l|}{ High Tech } \\
\hline Drugs & Drugs and medicines \\
\hline Information technology & $\begin{array}{l}\text { Office computing and accounting machines } \\
\text { Communications equipment and electronic } \\
\text { components } \\
\text { Electronic components and accessories and } \\
\text { communications equipment }\end{array}$ \\
\hline Aerospace / defense & $\begin{array}{l}\text { Guided missiles and space vehicles and parts } \\
\text { Ordinance except missiles } \\
\text { Aircrafts and parts }\end{array}$ \\
\hline \multicolumn{2}{|l|}{ Medium Tech } \\
\hline Instrumentation & Professional and scientific instruments \\
\hline Automotive & $\begin{array}{l}\text { Motor vehicles and other transportation } \\
\text { equipment, except aircraft }\end{array}$ \\
\hline Chemicals/ plastics & $\begin{array}{l}\text { Chemicals, except drugs and medicines } \\
\text { Basic industrial inorganic and organic } \\
\text { chemistry } \\
\text { Industrial inorganic chemistry } \\
\text { Industrial organic chemistry } \\
\text { Plastic materials and synthetic resins } \\
\text { Agricultural chemicals } \\
\text { All other chemicals } \\
\text { Soaps, detergents, cleaners, perfumes, } \\
\text { cosmetics and toiletries } \\
\text { Paints, varnishes, lacquers, enamels and } \\
\text { allied products } \\
\text { Miscellaneous chemical products } \\
\text { Rubber and miscellaneous plastics products }\end{array}$ \\
\hline \multicolumn{2}{|l|}{ Low Tech } \\
\hline Food and Beverages & Food and kindred products \\
\hline Metals & $\begin{array}{l}\text { Primary metals } \\
\text { Primary ferrous products } \\
\text { Primary and secondary non-ferrous metals }\end{array}$ \\
\hline Oil and Gas & $\begin{array}{l}\text { Petroleum and natural gas extraction and } \\
\text { refining }\end{array}$ \\
\hline
\end{tabular}




\section{APPENDIX B}

\section{List of service sectors (SIC codes) excluded from the M\&As data}

4 - $\quad$ Transportation, Communications, Electric, Gas, and Sanitary Services

5 - Wholesale Trade, Retail Trade

6 - $\quad$ Finance, Insurance, and Real Estate

7 - $\quad$ Services

- except 737: Computer Programming, Data Processing and Other Computer Related Services

8 - $\quad$ Services

- except 8711: Engineering Services

- except 873: Research, Development, and Testing Services

9 - Public Administration, and Non-classifiable Establishments 
TABLE 1 Multinomial logit model of the probability that companies have an alliance, mixed or M\&A strategy (experience variables excluded from the analysis).

\begin{tabular}{llll} 
& M\&A & Mixed & Mixed \\
Reference state & Alliance & Alliance & M\&A \\
\hline Constant & 11.50 & 2.86 & -8.63 \\
& $(3.24)^{* * *}$ & $(0.85)$ & $(-2.39)^{* *}$ \\
USA dummy & -0.35 & -0.22 & 0.13 \\
& $(-0.63)$ & $(-0.41)$ & $(0.23)$ \\
High-tech sectors & -3.92 & -0.83 & 3.09 \\
& $(-4.18)^{* * *}$ & $(-0.76)$ & $(3.28)^{* * *}$ \\
Medium-tech sectors & -1.73 & 0.00 & 1.73 \\
& $(1.91)^{*}$ & $(0.00)$ & $(1.94)^{*}$ \\
High patenting & -0.76 & -0.83 & -0.07 \\
intensity & $(-1.12)$ & $(-1.25)$ & $(-0.10)$ \\
Medium patenting & -0.88 & -0.72 & 0.16 \\
intensity & $(-1.64)$ & $(-1.40)$ & $(0.29)$ \\
Size & -0.52 & -0.13 & 0.39 \\
& $(-2.62)^{* * *}$ & $(-0.70)$ & $(1.90)^{*}$
\end{tabular}

Observations 135 Chi-squared $=40.06^{* * *}$ Percentage of cases correctly classified $=53$ percent Notes:

$\mathrm{z}$-scores in parentheses " $<<0.1,{ }^{* *} \mathrm{p}<0.05,{ }^{* * *} \mathrm{p}<0.01$

Coefficients in the third column are differences between the coefficients in the first and second column. The omitted variables are low-tech sectors and low patenting intensity. 
TABLE 2 Multinomial logit model of the probability that companies have an alliance, mixed or M\&A strategy (routines variables).

\begin{tabular}{llll} 
& M\&A & Mixed & Mixed \\
Reference state & Alliance & Alliance & M\&A \\
\hline Constant & -0.49 & -2.12 & -1.63 \\
& $(-0.57)$ & $(-1.86)^{*}$ & $(-1.41)$ \\
Alliance routines & -0.67 & -0.03 & 0.64 \\
& $(-2.76)^{* * *}$ & $(-0.15)$ & $(2.32)^{* *}$ \\
Mixed routines & -0.08 & 0.46 & 0.54 \\
& $(-0.47)$ & $(2.70)^{* * * *}$ & $(2.95)^{* * *}$ \\
M\&A routines & 0.54 & -0.56 & -0.084 \\
& $(3.25)^{* * * *}$ & $(-2.01)^{* *}$ & $(-0.47)$
\end{tabular}

Observations 135 Chi-squared $=100.20^{* * *}$ Percentage of cases correctly classified $=70$ percent

Notes:

z-scores in parentheses

${ }^{*} \mathrm{p}<0.1,{ }^{* *} \mathrm{p}<0.05,{ }^{* * *} \mathrm{p}<0.01$

Coefficients in the third column are differences between the coefficients in the first and second column. 
TABLE 3 Group means classified according to the preferences for different means of external appropriation of innovative capabilities (dependent variable)

Dependent Low-tech Medium- High-tech Low patent Medium patent High patent variable sector tech sector sector intensity intensityintensity

$\begin{array}{lcccccc}\begin{array}{l}\text { Alliance } \\ \text { preference }\end{array} & .04000 & .20000 & .76000 & .30000 & .48000 & .22000 \\ \begin{array}{l}\text { Mixed } \\ \text { preference }\end{array} & .05714 & .31400 & .62900 & .45714 & .40000 & .14286 \\ \begin{array}{l}\text { M\&A } \\ \text { preference } \\ \text { Total }\end{array} & .28000 & .42000 & .30000 & .44000 & .40000 & .16000 \\ & .13333 & .31100 & .55600 & .39259 & .42963 & .17778\end{array}$

$\begin{array}{llllll}\begin{array}{l}\text { Dependent } \\ \text { variable }\end{array} & \begin{array}{l}\text { Alliance } \\ \text { routine }\end{array} & \begin{array}{l}\text { Mixed } \\ \text { routine }\end{array} & \begin{array}{l}\text { M\&A } \\ \text { routine }\end{array} & \text { Size } & \begin{array}{l}\text { USA } \\ \text { dummy }\end{array} \\ \begin{array}{l}\text { Alliance } \\ \text { preference }\end{array} & 1.12000 & 1.20000 & 3.86000 & 3.01881 & .76000 \\ \begin{array}{l}\text { Mixed } \\ \text { preference }\end{array} & 2.82857 & 2.80000 & 1.65714 & 1.96292 & .68571 \\ \begin{array}{l}\text { M\&A } \\ \text { preference }\end{array} & 5.24000 & 1.06000 & .42000 & 2.47237 & .62000 \\ \text { Total } & 3.08889 & 1.56296 & 2.01481 & 2.54267 & .68889\end{array}$


TABLE 4 Results of the t-test for paired samples of companies with core business related strategic technology alliances or core business related M\&As

\begin{tabular}{|l|l|l|l|l|l|l|}
\hline Variable & \# of pairs & Corr & 2-tail sign & Mean & SD & SE Mean \\
\hline $\begin{array}{l}\text { core business } \\
\text { alliances }\end{array}$ & & & & 0.6308 & 0.439 & 0.048 \\
\hline & 82 & 0.36 & 0.001 & & & \\
\hline $\begin{array}{l}\text { core business } \\
\text { M\&As }\end{array}$ & & & & 0.7518 & 0.315 & 0.035 \\
\hline
\end{tabular}

Paired Differences

\begin{tabular}{|l|l|l|l|l|l|}
\hline Mean & SD & SE of Mean & t-value & Df & 2-tail sign \\
\hline-0.121 & 0.438 & 0.048 & -2.5 & 81 & 0.014 \\
\hline
\end{tabular}

$95 \%$ CI $(-.217,-.025)$ 
TABLE 5 Overview of support for the hypotheses

Hypotheses

1a High-tech sectors preference for alliances $1 \mathrm{~b}$ Low-tech sectors preference for M\&As 1c Medium-tech sectors preference for mix

2 Core business - M\&A; none core - alliances

3a Strong regime of appropriability - alliances $3 \mathrm{~b}$ Weak regime of appropriability - M\&As

$3 c$ Average regime of appropriability - mix

4 Routines drive choice
Support

Yes

Yes

Partial

Yes

No

No

No

Yes 
1.As explained in more detail in the section on 'Variables and measures' this differentiation into high-tech, medium-tech and low-tech is not only theoretically reconstructed but also supported by empirical evidence regarding different 'clusters' of sectors according to their R\&D intensity.

2. In Teece (1987, pp. 202-207) these alternative considerations are presented in detailed decision flow charts, an integration calculus and a comparison of contract and integration strategies that can help companies make decisions given different regimes of appropriability.

3. We do admit that the number of five alliances or M\&As is somewhat arbitrary but to include companies that have only one or two alliances or M\&As in two years and then to interpret this as a 'strategy' seems somewhat awkward in the light of the relatively large number of alliances and/or M\&As that other companies have.

4.We do not deny that small and medium sized firms can play an active role in creating both strategic technology alliances and M\&As. However, with the exception of the semiconductor and biotechnology industries, it seems that these smaller companies are less active in the field of alliances and M\&As than larger companies.

5.We did not follow the well-known practice to use the $\log _{n}$ of patents to control for the possible skewness in the data because some companies did not have patents and using the $\log _{\mathrm{n}}$ in those cases would lead to missing values.

6. Also, the exact degree to which companies in this population are internationally diversified is unknown for most of the European companies due to a lack of reliable data.

7.During our research we also applied discriminant analysis and standard regression analysis as additional methods. As we have a number of dummy variables in our analysis, this creates some methodological problems for the discriminant analysis with regard to the assumption of multivariate normality. There are some solutions to these problems, e.g. the size of both the sample and each of the final categorizations is quite large, one can control for outliers and check whether the correlation of the dummy variables with the other independent variables in each classified group in the discriminant analysis is of the same order of magnitude. When we used discriminant analysis these checks suggested that this method could be used. As far as regression analysis is concerned, we used the share of strategic technology alliances in the total number of external sources of innovation as the dependent variable. In that case that dependent variable would not be normally distributed as we have an upper limit of 1 and a lower limit of 0 . Again it is open to debate whether regression analysis is appropriate in the context of this research. Given these methodological problems, we decided that multinomial logit is most appropriate for our current research and we only report the findings of this logit analysis. However, the findings for both discriminant analysis and regression analysis were identical to the logit analysis with the same variables generating significant results. Having tested the hypotheses with three different statistical techniques that generate similar results, this suggests that our findings are quite robust. 